\title{
Prevalence and Possible Risk Factors of Malaria among Pregnant Women Attending To Antenatal Care at Umtalha Health Centre in Gezira State -Sudan
}

\author{
Eltagi A. M. Abdalla ${ }^{1}$, Logman A. M. Abdalla ${ }^{2}$, Wigdan A. H. Eltayeb ${ }^{3}$ \\ 1,3 (Department of Epidemiology, Faculty of Public and Environmental Health, University of Khartoum, Sudan) \\ ${ }^{2}$ (Ministry of Health, Gezira State, Sudan)
}

\begin{abstract}
Malaria in pregnancy is one of the leading causes of maternal and child morbidity and mortality worldwide, mainly in high endemic areas. Our study aimed to estimate the prevalence of and to identify the possible risk factors associated with Malaria infection among pregnant women attending to antenatal care at health center in Umtalha village in Gezira State, Sudan. Methods: A cross- sectional facility based study was conducted. A total of 332 pregnant women were selected. A structured questionnaire was used to collect data on socio-demographic characteristics and possible risk factors. Blood was screened for malaria parasite. Results: $42(12.7 \%)$ ) of respondents were found to be Malaria positivity, $97.6 \%$ of cases infected with Plasmodium falciparum and $2.4 \%$ (1/42) of cases infected with plasmodium vivax. The analysis showed there was relationship between age group, educational level, family income, family size and sleeping under ITNs at night and malaria positivity. $P$ values $=(<0.0001,0.0001,0.025,0.007$ and 0.036$)$ respectively. The results indicated there was association between parity, past history and knowledge of malaria and malaria positivity. $P$ values $=(0.042,0.011$ and 0.0003$)$ respectively. Conclusion: The study showed the prevalence of malaria among pregnant women was $12.7 \%$. the result showed the $P$. falciparum malaria is common in pregnant women
\end{abstract}

Keywords: Malaria, pregnant women, , risk factor, Gezira State, Sudan.

\section{Introduction}

Malaria in pregnancy is one of the leading causes of maternal and child morbidity and mortality worldwide, mainly in high endemic areas. About 125 million women are at risk of acquiring malaria infections during pregnancy, mainly in Africa where Plasmodium falciparum is the dominant malaria parasite in most parts of sub-Saharan Africa and hence responsible for most infections in pregnancy [1-3]. Plasmodium vivax is also a significant cause of maternal morbidity during pregnancy and of low birth weight in parts of Asia [2] and Latin America [4].Malaria in pregnancy can lead to miscarriage, premature delivery, low birth weight, congenital infection, and fetal as well as perinatal death [5].Malaria infection during pregnancy poses substantial risk to the mother, the foetus and the neonate; higher parasitaemia particularly in 2nd and 3rd trimesters, anaemia and altered placental integrity result in less nutritional support leading to low birth weight (LBW), abortion, still birth, premature birth and high infant morbidity/mortality [6]. In endemic areas, malaria in pregnancy is often asymptomatic, especially in cases of primigravidae; additionally the parasite may be undetectable in peripheral blood smears, causing the delay in disease treatment [7].

The prevalence and burden of malaria have declined markedly in the 21 st century, primarily due to the dramatic increase in the coverage of malaria interventions, with the usage of insecticide-treated nets (ITNs) increasing from $<2 \%$ in 2000 to 55\% in 2015 and the proportion of malaria cases adequately treated increasing from < $1 \%$ in 2005 to $16 \%$ in 2014 [8,9]. The prevalence of malaria among pregnant women in sub-Saharan Africa was 29.5\% in East and Southern Africa and 35\% in West and Central Africa [5]. In Gambia was 56.1\% [3]. In Ghana 12.6\% [10]. In Nigeria from 36.5\% - 51.7\% [11, 12]. In India 5.4\% [13].

Malaria is a public health problem in Sudan where the annual cases are 3,073,966 and deaths are 1,125, Plasmodium falciparum is responsible for $90 \%$ of all infections being the species associated with most severe cases, especially young children and pregnant women [14]. May studies was conducted in Sudan recorded various rates of malaria among pregnant women. These include $26.2 \%$ among pregnant women in Khartoum state [15]. 38.1\% among pregnant women in White Nile State in Ed-Duweim [16]. 13.7\% among pregnant women in eastern Sudan [17]. The aim of this study is to determine the prevalence of malaria parasite infection and to identify the possible risk factors among pregnant women attending to health center at Umtalha village in Gezira State - Sudan. 


\section{Materials And Methods}

Study design: A descriptive cross sectional facility based study was conducted among pregnant women attending health center at Umtalha village in Khartoum State, Sudan.

Study area: Umtalha is a large village located in El-Managil area in Gezira State, Central Sudan. The total population about ten thousand person, the main activities of population agricultural and breeding animals. Regarding public services there are four basic schools, two secondary schools, Khalwa for holly Quran, one dispensary and one health center.

Study population and sampling: The target study population including all pregnant women in their various trimesters seeking medication at antenatal care (ANC) in health center during study period from March to June 2016. The total number of pregnant women was (332).

Data collection: Data were collected from pregnant women by the following tools:

- Questionnaire: Informed consent from the selected participants was obtained. Pre tested structured direct administrated questionnaire was used to collect socio-demographic characteristics such as (Age group, educational status, employment, monthly income and family size), knowledge of malaria, family own ITN, using mosquito net, gestation period, parity, pregnancy gap and history of malaria. Questionnaire was designed in English and then translated into Arabic, the native language of respondents.

- Blood samples collection: Standard and careful laboratory procedure was adopted in collection of finger-prick blood samples by swabbing the area to be sampled with $70 \%$ alcohol and allowed to dry before collection. Thick and thin blood films were made on clean slides and labelled with corresponding number so the results would not be exchanged. Blood films were stained with Giemsa stain for 30 minutes as recommended by (WHO). Stained slides were examined under the light microscope using 100x oil immersion objective lens.

Data Analysis: Data were analyzed used SPSS (Statistical Package for Social Science) version 20. Chi-Square test was used to determine the significance differences between variables. Differences to be significant at level of p.value less than 0.05 .

\section{Socio-demographic characteristics:}

\section{Results}

A total of three hundred and thirty two pregnant women were included in this study. 63.3\% (210/332) of participants in age group $20-29$ years, $20.2 \%$ in age group 30-39 years, $9.6 \%$ less than 20 years old while $6.9 \%$ in age group 40-49 years. More than half of participants had secondary education level $(51.2 \%), 32.8 \%$ had basic or/primary education, $10.8 \%$ were graduated and $5 \%$ were illiterates women. Regarding employment most of women unemployed $85.2 \%$ (283/332). $65.1 \%$ of participants their monthly family income was low, $25.9 \%$ had middle income and $9 \%$ their income high. Regarding to family members $57.2 \%$ of participants their family more than 6 member, $18.7 \%$ had 6 members and 24.1\% less than 6 family members (Table 1).

\section{Laboratory findings:}

Among 332 pregnant women, the result shows $12.7 \%$ (42/332) of pregnant women were positive for malaria (Table 2). Regarding the malaria parasite species the laboratory findings show $97.6 \%$ (41/42) of cases infected with Plasmodium falciparum. While plasmodium vivax was seen in one case (1/42) $2.4 \%$. Plasmodium malariae and plasmodium. Ovale were not seen (Table 3).

\section{Relationship between characteristics of pregnant women and malaria positivity:}

Table 4 shows the prevalence of malaria among pregnant women according their characteristics. Regarding to age groups, the results show the prevalence increasing in age increase, high prevalence in age group $40-49$ years $30.4 \%$ ( 7 out of 23 ) followed by $30-39$ years $19.4 \%$ (13/67), by aged $20-29$ years $9.5 \%$ $(20 / 210)$ and $6.3 \%(2 / 32)$ in those less than 20 years old. The findings show there was statistical relationship between age group and malaria positivity $\left(\mathrm{P}<0.0001\right.$ at $\left.\mathrm{X}^{2}=23.437\right)$. In relation to education level, the results show high prevalence of malaria in illiterates women $41.2 \%$ (7/17) compared to $8.3 \%$ (3/36) in graduated women. The findings show there was statistical association between education level and malaria positivity $(\mathrm{P}=$ 0.0001 at $\left.X^{2}=21.139\right)$. The result show the malaria more prevalent among those have low monthly income $16.2 \%(35 / 216)$ compared to $7 \%$ and $3.3 \%$ in middle and high income respectively, the results show there was statistical significant $\left(P=0.025\right.$ at $\left.X^{2}=7.33\right)$. Regarding to family members (size) the findings show the prevalence of malaria was $21.3 \%$ (17/80) among pregnant women have more than 6 members in family, $16.1 \%$ (10/62) those their family members 6 and $7.9 \%(15 / 190)$ those their family members less than 6 . The results show there was statistical association $\left(P=0.007\right.$ at $\left.X^{2}=9.922\right)$. Regarding to sleeping under ITNs at night. The results show the prevalence of malaria was 14.9\% (37/249) among those sleeping under ITNs at night compared to $6 \%(5 / 83)$ among those don not sleep under ITNs at night, the results show there was statistical relationship between sleeping under ITNs at night and malaria positivity $\left(P=0.036\right.$ at $\left.\mathrm{X}^{2}=4.360\right)$. The results show there was no relationship between employment and family owns ITNs and malaria positivity $(P>0.05)$. 
Association between malaria positivity and some risk factors among pregnant women:

Table 5 demonstrates the association between malaria positivity and some risk factors. Regarding parity, the results show the malaria more prevalent in women those in primigravidae $24.2 \%(15 / 62)$ compared to $11.8 \%$ and $10.1 \%$ in those in secondigravidae and multigravidae respectively. The results show there was significant association $\left(\mathrm{P}=0.043\right.$ at $\left.\mathrm{X}^{2}=8.136\right)$. regarding to gestation period, the result show the prevalence in those in 2nd trimester $14.5 \%$ (25/172), $11.3 \%$ (12/106) among those in 1st trimester and 9.3\% (5/54) among those in 3rd trimester. The results show there was no statistical association between gestation period and malaria positivity $\left(\mathrm{P}=0.526\right.$ at $\mathrm{X}^{2}=1.284$ ). Regarding to history of malaria, the result show the malaria was more prevalent among women have previous malaria $16.2 \%$ compared to $6.6 \%$ among those have no previous malaria, the findings show there was statistical association between history of malaria and malaria positivity ( $\mathrm{P}$ $=0.011$ at $\mathrm{X}^{2}=6.480$ ). The knowledge of mode of malaria transmission play role in infection, the findings show the prevalence of malaria was high among women don't knew the mode of transmission $41.2 \%$ (7 out of 17) compared to $11.1 \%$ (35 out of 315 ) among those have knowledge of malaria transmission ( $P=0.0003$ at $\mathrm{X}^{2}$ $=13.194)$. Regarding to pregnancy gap our findings show there was no statistical association between pregnancy gap and malaria positivity $(\mathrm{P}>0.05)$.

Table 1: Characteristics of pregnant women attending to health center at Umtalha, Gezira Sate, Sudan

\begin{tabular}{|l|l|l|}
\hline Variable & Frequency & $\%$ \\
\hline Age group & 32 & 09.6 \\
\hline$<20$ & 210 & 63.3 \\
\hline $20-29$ & 67 & 20.2 \\
$30-39$ & 23 & 06.9 \\
\hline $40-49$ & 17 & 05.0 \\
\hline Educational level & 109 & 32.8 \\
\hline Illiterate & 170 & 51,2 \\
\hline Basic & 36 & 10.8 \\
\hline Secondary & \multicolumn{2}{|l|}{} \\
\hline Graduate & 49 & 14.8 \\
\hline Employment & 283 & 85.2 \\
\hline Employee & 216 & 65.1 \\
\hline Unemployed & 86 & 25,9 \\
\hline Monthly income & 30 & 09.0 \\
\hline Low & 190 & 57.2 \\
\hline Middle & 62 & 18.7 \\
\hline High & 80 & 24.1 \\
\hline Family size & \\
\hline$<6$ & & \\
\hline 6 & \multicolumn{2}{|l|}{} \\
\hline$>6$ & \multicolumn{2}{|l|}{} \\
\hline
\end{tabular}

Table 2: Prevalence of Malaria among respondents (pregnant women) attending to health center, Umtalha

\begin{tabular}{|l|l|l|}
\hline Malaria infection & No & Percent \% \\
\hline Positive (+ve) & 42 & 12.7 \\
\hline Negative (-ve) & 290 & 87.3 \\
\hline Total & 332 & 100.0 \\
\hline
\end{tabular}

Table 3: Prevalence and frequency of malaria parasite with respect to species

\begin{tabular}{|l|l|l|}
\hline Malaria parasite & No & Percent \% \\
\hline P. falciparum & 41 & 97.6 \\
\hline P. vivax & 01 & 2.4 \\
\hline P. malariae & 00 & 00.0 \\
\hline P. ovale & 00 & 00.0 \\
\hline
\end{tabular}

Table 4: Relationship between characteristics of pregnant women and Malaria positivity

\begin{tabular}{|c|c|c|c|c|c|}
\hline \multirow[b]{2}{*}{ Variable } & \multicolumn{2}{|c|}{ Malaria N(\%) } & \multirow{2}{*}{$\begin{array}{l}\text { Total } \\
\mathrm{N}(\%)\end{array}$} & \multirow[b]{2}{*}{ Chi-Square } & \multirow[b]{2}{*}{$\mathrm{P}$.value } \\
\hline & Positive & Negative & & & \\
\hline \multicolumn{6}{|l|}{ Age group } \\
\hline$<20$ & $02(0.6)$ & $30(09.0)$ & $32(09.6)$ & & \\
\hline $20-29$ & $20(06.0)$ & $190(57.2)$ & $210(63.3)$ & 23.437 & $<0.0001 *$ \\
\hline $30-39$ & $13(03.9)$ & $54(16.3)$ & $67(20.2)$ & & \\
\hline $40-49$ & $07(02.1)$ & $16(04.6)$ & $23(06.9)$ & & \\
\hline \multicolumn{6}{|c|}{ Educational level } \\
\hline Illiterate & $07(02.1)$ & $10(03.0)$ & $17(05.1)$ & & \\
\hline Basic & $20(06.0)$ & $89(26.8)$ & $109(32.8)$ & 21.139 & $0.0001^{*}$ \\
\hline Secondary & $12(03.6)$ & $158(47.6)$ & $170(51.2)$ & & \\
\hline Graduate & $03(0.9)$ & $33(09.9)$ & $36(10.8)$ & & \\
\hline
\end{tabular}




\begin{tabular}{|l|l|l|l|l|l|l|}
\hline Employment & $05(01.5)$ & $44(13.3)$ & $49(14.8)$ & 0.311 & 0.577 & \\
\hline Employee & $37(11.1)$ & $246(74.1)$ & $283(85.2)$ & & & \\
\hline Unemployed & $35(10.4)$ & $181(54.7)$ & $216(65.1)$ & & & \\
\hline Monthly income & $06(01.8)$ & $80(24.1)$ & $86(25,9)$ & 7.330 & $0.025^{*}$ & \\
\hline Low & $01(0.3)$ & $29(08.7)$ & $30(09.0)$ & & & \\
\hline Middle & & & & & & \\
\hline High & $15(04.5)$ & $175(52.5)$ & $190(57.2)$ & & & \\
\hline Family size & $10(03.0)$ & $52(15.7)$ & $62(18.7)$ & 9.922 & $0.007^{*}$ & \\
\hline$<6$ & $17(05.1)$ & $63(19.0)$ & $80(24.1)$ & & & \\
\hline 6 & $10(03.0)$ & $90(27.1)$ & $100(30.1)$ & 0.910 & 0.340 & \\
\hline$>6$ & $32(09.6)$ & $200(60.3)$ & $232(69.9)$ & & \\
\hline Family owns ITN \\
\hline $\begin{array}{l}\text { Yes } \\
\text { No }\end{array}$ & $05(01.5)$ & $77(23.5)$ & $83(25.0)$ & 4.360 & $0.036^{*}$ & \\
\hline Slept under ITN & $37(11.1)$ & $212(64.9)$ & $249(75.0)$ & & \\
\hline Yes
\end{tabular}

$* \mathrm{P}$-value $<0.05$ considered significant at CI $95 \%$

Table 5: Association between malaria positivity and some risk factors among pregnant women

\begin{tabular}{|c|c|c|c|c|c|}
\hline \multirow[b]{2}{*}{ Variable } & \multicolumn{2}{|c|}{ Malaria N(\%) } & \multirow{2}{*}{$\begin{array}{l}\text { Total } \\
\mathrm{N}(\%)\end{array}$} & \multirow[b]{2}{*}{ Chi-square } & \multirow[b]{2}{*}{ P .value } \\
\hline & Positive & Negative & & & \\
\hline \multicolumn{6}{|l|}{ Parity } \\
\hline Primgravidae & $15(04.5)$ & $47(14.2)$ & $62(18.7)$ & & \\
\hline Secondigravidae & 14(04.2) & 105(31.6) & $119(35.8)$ & 8.136 & $0.0433 *$ \\
\hline Thirdigravidae & $08(02.4)$ & $74(22.3)$ & $82(24.7)$ & & \\
\hline Multigravidae & $07(02.1)$ & $62(18.7)$ & $69(20.8)$ & & \\
\hline \multicolumn{6}{|l|}{ Gestation period } \\
\hline 1st trimester & $12(03.6)$ & 94(28.3) & $106(31.9)$ & & \\
\hline 2nd trimester & $25(07.5)$ & $147(44.3)$ & $172(51.8)$ & 1.284 & 0.526 \\
\hline 3rd trimester & $05(01.5)$ & $49(14.8)$ & $54(16.3)$ & & \\
\hline \multicolumn{6}{|l|}{ Pregnancy gap } \\
\hline 2 years & $31(09.3)$ & $185(55.8)$ & $216(65.1)$ & & \\
\hline 3 years & $08(02.4)$ & $78(23.50$ & $86(25,9)$ & 1.698 & 0.4277 \\
\hline > years & $05(01.5)$ & $25(07.5)$ & $30(09.0)$ & & \\
\hline \multicolumn{6}{|l|}{ History of malaria } \\
\hline Yes & 34(10.2) & $176(53.1)$ & $210(63.3)$ & 6.480 & $0.011 *$ \\
\hline No & $08(02.4)$ & $114(34.3)$ & $122(36.7)$ & & \\
\hline \multicolumn{6}{|c|}{$\begin{array}{l}\text { Knowledge of malaria } \\
\text { transmission }\end{array}$} \\
\hline Knew & $35(10.6)$ & $280(84.3)$ & $315(94.9)$ & 13.194 & $0.0003 *$ \\
\hline Don't Knew & $07(02.1)$ & $10(03.0)$ & $17(05.1)$ & & \\
\hline
\end{tabular}

$* \mathrm{P}$-value $<0.05$ considered significant at CI 95\%

\section{Discussion}

Malaria disease is dangerous especially an infection with Plasmodium falciparum is more hazardous during pregnancy. The present study attempted to estimate malaria prevalence and to identify the associated possible risk factors in pregnant women. The overall prevalence of malaria among pregnant women in this study was $12.7 \% \%$. This result similar with that reported among pregnant women in Eastern Sudan 13.7\% [17]. In Ghana $12.6 \%$ [10]. Our result was lower than that found in Sudan; which is found $26.2 \%$ in Khartoum state [15], and 38.1\% in White Nile state in Ed-Duweim [16]. Also lower than that found in Gambia was $56.1 \%$ [3]. In Nigeria from $36.5 \%$ - 51.7\% [11,12]. Our finding was greater than that found in pregnant women in India 5.4\% [13]. Regarding to malaria parasite species, our findings show the Plasmodium falciparum is more prevalence 97.6\%. this result similar with that reported in Sudan in Ed-Duweim [16]. Also similar with reported by CDC; The most Plasmodium falciparum infection occur in sub Saharan Africa and the P. falciparum has been shown to be more common in pregnant than non pregnant women [18]. The results show that, the malaria more prevalent among pregnant women in age group 40-49 years followed women in age 30-39 years. There was strong statistical association between age and malaria positivity $(\mathrm{P}<0.0001)$. this finding consist with that recorded in Nigeria [19]. In relation to education level, the study show high prevalence of malaria in illiterates women $41.2 \%$ compared to $8.3 \%$ in graduated women, the findings show there was statistical association between education level and malaria positivity $(\mathrm{P}=0.0001)$. Our findings similar with that found among Pregnant Women in Nigeria; illiterates pregnant women had the highest prevalence rate of malaria[20]. Family income have contributing in malaria infection, our findings showed the prevalence was higher among those have low income $16.2 \%$ than high income $3.3 \%$. The result show there was statistical association between malaria positivity and family income $(\mathrm{P}=0.025$ Regarding to family members, our result show the prevalence of 
malaria increase with family members increasing, there statistical relationship between $(P=0.007)$. Sleeping under ITNs at night very important to protect person from mosquitoes' bites. The study show the prevalence of malaria was more prevalent among those sleeping under ITNs at night compared to those don not sleep under ITNs at night, the results show there was statistical relationship between sleeping under ITNs at night and malaria positivity $(\mathrm{P}=0.036)$. The result similar with many studies shown that ITNs effective in controlling malaria in pregnant women and that the use of ITNs significantly reduce the prevalence and mean parasite load of malaria parasitameia [6]. In relation to parity, our findings show the malaria more prevalent among women those in primigravidae than those in secondigravidae and multigravidae. The results show there was significant association $(\mathrm{P}=0.043)$. Our result agree with that found in Nigeria by Ivoke $\mathrm{N}$ et al, they mention that falciparum malaria parasitaemia was associated with the parity the prevalence decline with increase gravidity[21]. This results disagree with that found by Adam I et al in Eastern Sudan, no significant association between malaria and parity[17]. Regarding to previous infection of malaria, the result show the malaria was more prevalent among women have previous infection of malaria $16.2 \%$ compared to $6.6 \%$ among those have no previous infection of malaria, the findings show there was statistical association between history of malaria and malaria positivity $(\mathrm{P}=0.011)$. Our study revealed that, there was no statistical association between employment, family owns ITNs gestation period and pregnancy gap and malaria positivity $(\mathrm{P}>0.05)$.

\section{Conclusion}

The study showed the prevalence of malaria among pregnant women was $12.7 \%$. the result showed the P. falciparum malaria is common in pregnant women at study area. The result show age group, educational level, family income, family size, sleeping under ITNs at night, parity history of malaria infection and knowledge of malaria transmission were considered factors associated with malaria positivity.

\section{Acknowledgments}

The authors would like to thanks all pregnant women participated in this study. Also we thanks all staff in health center at Umtalha.

\section{Conflict of Interests}

The authors hereby declare to have no conflict of interests.

\section{Authors' contributions}

Eltagi A.M. Abdalla conceived the research idea, designated the study, data collection and analysis. Logman A.M. Abdalla involved in laboratory investigation. Wigdan A.H. Eltayeb contributed in data collection and analysis.

\section{References}

[1] Lopez-Perez M, Pacheco MA, Buritica L, Escalante AA, Herrera S and and Arevalo-Herrera M. Malaria in pregnancy: a passive surveillance study of pregnant women in low transmission areas of Colombia, Latin America. Malaria J. 2016; 15:66

[2] Rijken MJ, Gready R, Boel ME, Poespoprodjo R, Singh N, Syafruddin D, et al. Malaria in pregnancy in the Asia-Pacific region. Lancet Infect Dis.2012; 12:75-88.

[3] Williams J, Njie F, Cairns M, Bojang K, Coulibaly SO, Kayentao K, et al. Non-falciparum malaria infections in pregnant women in West Africa. Malaria J. 2016; 15:53

[4] Brutus L, Santall J, Schenider D, Avila JCand Deloron P. Plasmodium vivax malaria during pregnancy, Bolivia. Emerg Infect Dis. 2013; 19:1605-11.

[5] Sharifi-Mood B. Malaria in Pregnant Women. Int J Infect. 2015; 2(3): e22992.

[6] Maureen FD, Grace RC and Galoria AO. Prevalence of Malaria Parasitaemia among Pregnant Women Attending Three Selected Health Centers in Ideato South Local Government Area, Imo State. Obstet Gynecol Int J. 2016; 4(3): 00111

[7] Zablon KN, Kakilla C, Lykina T, Minakova V, Chibago A and kaeva BZ. Prevalence of Plasmodium falciparum Malaria among Pregnant Students in Dodoma Region, Tanzania: No Cases Have Been Detected. Malaria Research and Treatment. 20-15; doi.org/10.1155/2015/473203

[8] Patrick G. T. Walker1*, Jessica Floyd1, Feiko ter Kuile2,3, Matt Cairns4. Estimated impact on birth weight of scaling up intermittent preventive treatment of malaria in pregnancy given sulphadoxine pyrimethamine resistance in Africa: A mathematical model. PLOS Medicine | DOI:10.1371/journal.pmed.1002243.

[9] World Health Organization. World Malaria Report 2015. Geneva:

[10] Tay SCK, Agboli E, Abruquah HH and Walana W. Malaria and Anaemia in Pregnant and Non-Pregnant Women of Child-Bearing Age at the University Hospital, Kumasi, Ghana. Open Journal of Medical Microbiology. 2013; 3:193-200

[11] Taura, DW and Oyeyi, TI. Prevalence of Malaria Parasites in Pregnant Women Attending SIR Muhammad Sunusi Special Hospital, KANO, Nigeria. Bayero Journal of Pure and Applied Sciences. 2009; 2(1):186 - 188

[12] Bawa, JA, Auta, T and Liadi, S. Prevalence of Malaria: Knowledge, Attitude and Cultural Practices of Pregnant Women in Katsina Metropolis, Nigeria. European Scientific Journal. 2014;10(21): ISSN: 148 - 167

[13] Sohail M, Shakeel S, Kumari S, Bharti A, Zahid F, Anwar S, et al. Prevalence of Malaria Infection and Risk Factors Associated with Anaemia among Pregnant Women in Semiurban Community of Hazaribag, Jharkhand, India. BioMed Research International. 2015: doi.org/10.1155/2015/740512

[14] Hani YZ, Badreldin EA and Hayder EB. Biochemical Profiles of Children with Severe Plasmodium falciparum Malaria in Central Sudan: a case-control study. Al Neelain Medical Journal. 2013; 3(8):15- 23. 
[15] Samia AO, Eltahir AG, Abdalla HS and Hashim AA. "Pregnancy-Associated Malaria in Sudan: Prevalence and Possible Risk Factors. The Open Tropical Medicine Journal. 2011; 4: 6-10.

[16] Gabbad AA, Ahmed AI and Elawad MA. Malaria in Pregnant Women Attending Antenatal Clinic at Ed-Duweim Hospital, Sudan. European Academic Research. 2014; 2(1): 573-580

[17] Adam I, Khamis AH and Elbashir M. Prevalence and risk factors for Plasmodium falciparum malaria in pregnant women of eastern Sudan. Malaria Journal 2005, 4:18

[18] CDC (2004). Malaria in pregnancy (404) 639-3534

[19] Abe AF and Olusi TA. Seroprevalence of Malaria Parasite Infection among Pregnant Women Attending Two Tertiary Health Facilities in Akure Ondo State Nigeria. J Bacteriol Parasitol 2015; 5(4): doi:10.4172/2155-9597.1000194

[20] Adefioye OA, Ad eyeba OA, Hassan WO and Oyeniran OA. Prevalence of Malaria Parasite Infection among Pregnant Women in Osogbo, Southwest, Nigeria. American-Eurasian Journal of Scientific Research 2007; 2 (1): 43-45

[21] Ivoke N, Ivoke ON, Okereke NC and Eyo JE. Falciparum Malaria Parasitameia among Pregnant Women Attending Antenatal Clinics in a-Guinea- Savannah Zone, South-western Ebonyi State Nigeria.International journal of Scientific and Engineering Research 2013; 4(9):1876-1883 